\title{
ECOLOGÍA DE SABERES Y PEDAGOGÍA: UNA CRÍTICA SOCIOCULTURAL FRENTE A LA CRISIS CAPITALISTA EN LATINOAMÉRICA
}

\author{
Yesid Niño Arteaga \\ Historia de la educación en América Latina \\ yesidnio@hotmail.com
}

\begin{abstract}
Resumen
Este trabajo de escritura muestra un recorrido analítico a través de las posibles dimensiones de una pedagogía latinoamericana, apoyándose en parte del pensamiento sociológico de Boaventura de Sousa Santos, se busca repensar la relación histórico-ontológica de la pedagogía en la cultura contemporánea. Con dicha relación el documento se aproxima a construir una comprensión del concepto de pedagogía a partir de indagaciones a la realidad sociocultural contemporánea, estableciendo en su eventualidad discursiva una crítica filosófica que involucra, la época, el carácter cultural y el sentido de lo humano presentes en el acto educativo. Sobre este punto el documento presenta interpretaciones que posibilitan una dirección de crítica respecto a la crisis del paradigma del progreso asentado en el capitalismo global. Así el artículo establecerá posibles comprensiones desde el ámbito hermenéutico que escindan una posible caracterización de lo pedagógico y a su vez replieguen otro sentido en su discurso dando lugar a la heterogeneidad que implica una ecología de saberes.
\end{abstract}

Palabras clave: Pedagogía, capitalismo global, teoría crítica, filosofía de la cultura, ecología de saberes. 


\title{
ECOLOGY OF KNOWLEDGE AND PEDAGOGY: A SOCIOCULTURAL CRITIQUE OF THE CAPITALIST CULTURE IN LATIN AMERICA
}

\begin{abstract}
This work demonstrates an analytical journey through the possible dimensions of a Latin American pedagogy. Relying in part on the sociological contemplation of Boaventura de Sousa Santos, it seeks to rethink the historical-ontological relationship of pedagogy in contemporary culture. The investigation aims to build an understanding of the concept of pedagogy based on inquiries into the contemporary sociocultural reality, establishing in its discursive eventuality a philosophical critique that involves time, cultural character, and the human essence present in education. The document presents interpretations that enable a type of criticism regarding the crisis of the progress paradigm based in global capitalism. The article establishes possible perceptions from the hermeneutic scope that divides a possible characterization of the pedagogical while replicating another sense in its discourse, giving rise to the heterogeneity that implies an ecology of knowledge.
\end{abstract}

Keywords: Pedagogy, global capitalism, critical theory, philosophy of culture, knowledge ecology.

\section{ECOLOGIA DO CONHECIMENTO E PEDAGOGIA: UMA CRÍTICA SOCIOCULTURAL CONTRA A CRISE CAPITALISTA NA AMÉRICA LATINA}

\begin{abstract}
Resumo
Este documento escrito mostra um percurso analítico através das possíveis dimensões de uma pedagogia latino-americana, baseada em parte no pensamento sociológico de Boaventura de Sousa Santos, que busca repensar a relação histórico-ontológica da pedagogia na cultura contemporânea. Com esta relação o documento aborda construir uma compreensão do conceito de pedagogia de indagações à realidade contemporânea sociocultural, estabelecendo em seu acontecimento discursivo uma crítica filosófica envolvidos, o tempo, o caráter cultural e o sentido de humanidade presente em o ato educativo. Neste ponto, o documento apresenta interpretações que permitem uma direção de crítica à crise do paradigma de progresso estabelecido no capitalismo global. Assim este Artigo estabelecera possíveis comprensões de campo hermenêutico que divides uma possível caracterização do pedagógico replieguen outro sentido em seu discurso dando origem a heterogeneidade que implica uma ecologia de saberes.
\end{abstract}

Palavras-chave: Pedagogia, capitalismo global, teoria crítica, filosofia da cultura, ecologia de saberes 


\section{Introducción}

¿Sería drástico admitir que lo contemporáneo representa una época donde predomina la vaciedad del ser humano? No puede resultar quimérica la pregunta frente al presupuesto de que el capitalismo global asegura esa vaciedad, debido a que no es ninguna coincidencia que la relación histórica con el presente tienda a asimilarse a partir de las generalidades lógicas del neoliberalismo mediático y financiero. En la vida y desde la labor docente la anterior es una situación que también es visible en la escuela, así lo enseña Zambrano Leal (2009), puesto que en el discurso que envuelve el conocimiento educativo parece observarse cierta predilección por las técnicas y modos de pensar más tradicionales y conservadores provocando así una mera reproducción de la lógica económica-política y la moral dominante de la época.

Según esto no es una exageración decir con Santos ${ }^{1}$, que las relaciones humanas se presentan en la actualidad como dependientes a los criterios de explotación, acumulación, crisis y vacío, lo que quizás vaya consolidando la reproducción de un conocimiento a partir de la falta de crítica, o de una semi-crítica, cuya pretensión de sujeto, según $\operatorname{Han}^{2}$ involucra la regularización y la uniformización, lo que sin duda proporciona el riesgo de mantener las fronteras de miseria así como la creciente desorientación del mundo en el hiperconsumo, que siguiendo a Lipovetsky y Serroy ${ }^{3}$, puede tratarse como la fuente del capitalismo global, asimilación del hados profuso de constituir la empresa o la industria de la reducción del otro.

De esta manera se promueve la emergencia de un análisis sobre la presencia histórica del otro en la razón pedagógica y cultural, debido a que la relación cultura-educación es más fagocitaria que inherente, por eso es preciso abordar la realidad desde una crítica filosófica, que en este artículo se tratará como posible referente que permite indagar en la actualidad y/o estado del arte de la realidad ontológica de la época, enfoque que también permite establecer diálogos con la pedagogía en medio del exasperante entramado de lo real-razonable que más bien sobresale como un telos para la generación y reproducción de competencias.

Lo humano no puede legitimarse como fin y medio del criterio de la explotación. Siendo así se configura el interrogante: ¿la educación del ser humano del presente estaría respondiendo críticamente y a su vez proyectando una resistencia al criterio de dominio y poder capitalista? Bajo esta consideración se propone una dimensión hermenéutica para abordar parte de la dimensión histórica de la realidad social representada en la pedagogía y en su profunda relación con el pensamiento filosófico, así se obtendrán comprensiones que inquieran sobre

1. Boaventura de Sousa Santos, Descolonizar el saber. Reinventar el poder (Santiago de Chile: LOM, 2014) y Democracia y transformación social (Bogotá: Siglo XXI, 2017).

2. Han Byung-Chul. La expulsión de lo distinto. (Madrid: Herder, 2017).

3. Gilles Lipovetsky y Jean Serroy. La cultura-mundo (Barcelona: Anagrama, 2010). 
las tendencias del conocimiento pedagógico, según Martínez Boom ${ }^{4}$ al ser éste el foco de las prácticas educativas actuales, pero también un posible eje de la consolidación ideológica en la cultura dominante.

A partir de esto, a continuación se presentará un estudio crítico y filosófico apoyado en la hermenéutica, presentando parte de los posibles referentes sintéticos en torno a algunas definiciones de la pedagogía clásica y moderna que se fundan sobre el individuo, sujeto, alumno, profesor, situación que permite en el presente trabajo, perseguir un objetivo de estudio que apunta a mostrar las posibilidades de una renovación discursiva dentro de lo que podría considerarse una pedagogía latinoamericana ${ }^{5}$.

\section{La pedagogía, su apuesta por la racionalidad abismal y posibilidades de ruptura}

La idea de una "pedagogía latinoamericana" no puede parecer extraña al contexto latinoamericano. Con Dussel (1980) por ejemplo, la educación tiene un origen más antiguo y diverso que la misma historia de la lengua castellana más allá de la transculturación/aculturación adjunta a la colonización de los territorios indígenas, lo que involucra el advenimiento de los conocimientos y prácticas fijadas en el pensamiento europeo a partir del desarrollo del concepto de "escuela". Concepto que, siguiendo a Martínez Boom, se funda y a la vez asegura a la sociedad disciplinaria, puesto que está ligada a los procesos de homogenización y regulación del saber en un espacio y tiempo delimitado a través de la especificidad y determinación de una práctica disciplinaria. Recordemos que "la función de la escuela es de orden político y moral... acontecimiento ligado a una promesa: ¡entrégame a tu hijo, yo te devuelvo un ciudadano!"6, por tal motivo es un espacio para el ordenamiento y consolidación de un tipo definido de discurso, y por tanto de identidades fijas y derivadas de ese discurso: el maestro, el alumno, el conocimiento, la técnica, la disciplina, que terminan siendo pautas para jerarquizar las clases que componen lo social.

En este punto cabe mencionar que gran parte de las congregaciones que arribaron con la colonización, sobre todo Jesuitas y Dominicos en el caso de las colonias neogranadinas, establecieron sus prácticas educativas en las "doctrinas",

4. Alberto Martínez Boom, Verdades y mentiras sobre la escuela (Bogotá: Editorial Aula, 2015).

5. Este concepto se aborda a partir de una aproximación a la noción de "anti-pedagógica" propuesta por Enrique Dussel en su obra La pedagógica latinoamericana (Bogotá: Nueva América, 1980), http:// bibliotecavirtual.clacso.org.ar/clacso/otros/20120423090342/historia.pdf (jueves, 10 de agosto de 2017), establece un relevante análisis desde una crítica a la racionalidad colonial, presentando el concepto de "pedagógica", en relación con la filosofía y la conciencia política que es vinculada a todos los actos de aprendizaje, no solo en lo educativo (maestro-discípulo) sino en la cotidianidad (médicoenfermo, político-ciudadano) a partir de una caracterización de la erótica y la política como parte de la multiplicidad de los fenómenos sociales de Latinoamérica. Pero desde el inicio de la obra, Dussel deja de lado el concepto de pedagogía, logrando establecer una sencilla aproximación a su idea de ciencia de la enseñanza y del aprendizaje, lo que corre el riesgo de mantener vacíos frente a la comprensión de este concepto.

6. Martínez Boom. "Verdades y mentiras sobre la escuela”, 20. 
más que en las enseñanzas, de la religión católica y la lengua oficial del monarca ${ }^{7}$, ya que en el siglo XVIII se emprendía en Europa el programa de lo que fue un principio de educación popular-religiosa, proceso que prosperaría con Lutero, Delanchton y Calvino, pero que tuvo como referente al brutal y desafortunado programa de colonización de los europeos frente a los territorios americanos.

Un ejemplo tardío de este proceso de educación popular-religiosa es el conocimiento pedagógico de Comenio: "la escuela, al intentar formar al hombre debe procurar formarlo totalmente para hacerle igualmente apto para los negocios de esta vida que para la eternidad"8, idea que conforma no solo el inicio de un enfoque y un método educativo, sino a su vez un claro ejemplo de que la lógica de una pedagogía eurocéntrica se cimentó en el supuesto de formar seres morales, formar seres de fe, pero sobre todo seres aptos para la organización de una ciudadanía propia de la época, teniendo en ese entonces como base de lo social al modelo feudal que da pie al modelo capitalista, que desconoce un locus de enunciación por fuera de lo que en la actualidad Santos define como la racionalidad abismal, que es contigua a representaciones en las que el criterio de lo humano permanece paralelo a la desorientación. Por ejemplo: usted es pobre, entonces, aparece lo malo; él es el capital, entonces, resulta lo bueno'.

Cabe aclarar que esto no es un atentado contra su trascendencia histórica, pero es preciso señalar que, apoyándonos en la investigación de Noguera ${ }^{\mathbf{1 0}}$, el trabajo de Comenio responde a una construcción del conocimiento didáctico, pero que no se centra específicamente en el proceso y en el desarrollo del conocimiento pedagógico, pädagogik, que empieza a consolidarse en el siglo XVIII con Rousseau $\mathrm{y}$ a fortalecerse a inicios del siglo XIX con autores como Herbart y Willmann. De esta manera se delimitan las vertientes teóricas del fenómeno educativo conocidas actualmente como pedagogía y didáctica, la primera respondiendo a la dimensión de cómo enseñar y la segunda al cómo aprender. Dicotomía simplista pero que a lo largo del siglo XIX y XX arroja importantes reflexiones y contenidos teóricos acerca de las prácticas de aprendizaje y enseñanza. De este modo empieza a formarse una disciplina encargada de las fronteras del aprendizaje (didáctica) y otra encargada de las fronteras de la enseñanza (pedagogía), lo que ubicó a la pedagogía en estrecha relación con el campo teórico que durante el siglo XIX asumió el contenido cientificista del positivismo y la composición política de la sociedad capitalista europea.

7. Martínez Boom, “Verdades y mentiras sobre la escuela”, 98-110.

8. Juan Amós Comenio, Páginas escogidas (Buenos Aires: A-Z Editora, 1996), 65.

9. Así la racionalidad abismal, comprende una forma de dicotomía entre el ser y el no-ser perjudicial a toda dimensión humana, pobre-rico, legal-ilegal, culto-inculto, racional-no racional, verdaderofalso, científico-no científico, levantamiento de abismos sobre lo real, donde la apariencia del poder económico logra trascender la inconsistencia epistemológica del otro desconocido para arrinconarlo con extensiones de hambre, de miseria, explotación laboral como designios cuasi sagrados del monarca o terrateniente. De Sousa Santos, "Descolonizar el saber. Reinventar el poder".

10. Carlos Noguera Ramírez, "La constitución de las culturas pedagógicas modernas: una aproximación conceptual”. En: Revista Pedagogía y Saberes. Universidad Pedagógica Nacional. № 33 (2010): 9-25. 
En este sentido y siguiendo los postulados de Zambrano ${ }^{11}$, la pedagogía parece encontrase como algo por fuera de la realidad concreta de la escuela y hasta de la realidad sociocultural y de sus numerosas problemáticas, entendiéndose irónicamente como conocimiento de la realidad social solamente a partir de las designaciones de un grupo élite de expertos.

Pero al contrario, y siguiendo los planteamientos del filósofo colombiano Guillermo Hoyos Vásquez ${ }^{12}$, la pedagogía tiene que pensarse y practicarse bajo formas que precisen su transformación a través del diálogo con las realidades educativas, porque la pedagogía es lo que también puede contribuir a trazar una apertura epistemológica en el devenir de lo humano. Por eso en preguntas aparente simples como: ¿qué valores humanos y qué conocimientos se desglosan en lo educativo?, ¿en este espacio, se está respondiendo críticamente al modelo de la cultura-global o a las distinciones de los contextos en alteridad?, ¿se puede descifrar al pensamiento pedagógico como algo inacabado, como el fulgor de una crítica desde lo distinto?, ¿la escuela aspira a continuar ejercitando la racionalidad que ansía la acumulación de capital o a la fundación de reverencias?

En este sentido el atrevimiento que sostiene a la pedagogía es que ella tiene el "propósito social de transformación de la civilidad moderna para la creación de una cultura del pluralismo y de los derechos humanos, de la aceptación de las diferencias y de la formación para la democracia"13. Tal cual enseña el filósofo Guillermo Hoyos Vásquez la pedagogía, y quizás todo el aparato orgánico de la educación, deba esforzarse en adelantarse críticamente al paradigma de la razón monológica y reflexiva que ostenta la pasividad o la docilidad como ejemplos de una conciencia y de una subjetividad carente de cultura política. Por eso para Guillermo Hoyos Vásquez es totalmente admisible "un cambio radical de paradigmas"14 tanto para la filosofía como para la dirección teórico-política de la pedagogía.

Con lo que se hace posible proponer(se) la tarea de reafirmar otros sentidos dentro de los saberes pedagógicos así como en las prácticas educativas, multiplicidades-otras que puedan revitalizar y humanizar el saber y las prácticas que pueden ser analizadas y comprendidas a partir de las ciencias de la educación, entre ellas la pedagogía, estableciendo la idea de Deleuze ${ }^{15}$ de "líneas de fuga" sobre los modos de saber que clausuran, uniformizan o pretenden mantener la hegemonía.

11. Armando Zambrano Leal, “Aprendizajes y pedagogía en Philippe Meirieu”, Revista Praxis Educativa. Universidad Nacional de La Pampa. N 13 (2009): 10-24.

12. Guillermo Hoyos Vásquez, Ensayos para una teoría discursiva de la educación (Bogotá: Civitas, 2012), 293.

13. Hoyos Vásquez, "Ensayos para una teoría discursiva de la educación”, 64.

14. Hoyos Vásquez, "Ensayos para una teoría discursiva de la educación", 42.

15. Gilles Deleuze, Dos regímenes de locos (Buenos Aires: Pre-textos, 2008), 372. 


\section{Pedagogía versus re-producción educativa}

Ahora bien, ¿qué puede decirse sobre la pedagogía?, si es sabido que en la actualidad todavía permanece en un claroscuro el conflicto teórico-práctico entre la definición de pedagogía y otros conceptos propios del fenómeno educativo. Así el concepto de didáctica establece la contraposición más distinguida sobre todo desde su élite académica asentada en su mayoría en el sector privado. Pero cabe mencionar que la política, la historia, la filosofía y la sociología complementan el cuerpo teórico-práctico de la pedagogía como experiencia creada y revitalizada continuamente en el ámbito social.

Para pensadores de la pedagogía crítica como Freire ${ }^{16}$ y McLaren (1984) la pedagogía supone la creación de medios para comprender desde la condición humana las realidades políticas de los oprimidos en toda su complejidad y radicalidad, proponiendo a su vez que el espacio de lo educativo debe pensarse y hallarse a partir del enfrentamiento con los modelos de explotación social que entran en antagonismo con la vida.

Estos autores conciben en sus postulados teóricos una perspectiva distinta a la lógica abismal del capitalismo, dirigiéndose intelectualmente contra la proyección existente de los sujetos bancarios, encarnando la pedagogía en la emergencia de una cultura ética y política para así extender la posibilidad de "continuar hablando de sueños, utopía o justicia social"17, puesto que para la pedagogía no existe una relación por fuera del mundo del otro o por fuera del mundo de la vida.

Recordemos que para Zambrano ${ }^{18}$ el mundo de la vida suministra las vertientes epistémicas para comprender la dimensión pedagógica como un referente y un escenario propicio para suscitar tanto los actos de enseñanza como los actos de aprendizaje.

Frente a lo anterior siguen siendo legítimas las siguientes preguntas ¿qué clase de saber pedagógico se hace preciso para la vida y para una cultura política que no sea violenta ni injusta? ¿Qué tipo de valores humanos congregan el ámbito actitudinal que está por fuera de la reverencia a la burocracia? Si analizamos la superficialidad de estas preguntas como si la realidad fuera una obra de arte que suscita "la liberación de cualquier acto egoísta"19, estas preguntas enseñan los siguiente presupuestos: 1) que lo cognitivo y lo actitudinal no pueden seguir siendo la reproducción y manutención del sendero del sistema-verdad-capitalista, y 2) que la pedagogía no puede perseguir el rumbo social que desemboca en el neoliberalismo y el hiperconsumo.

16. Paulo Freire, La educación como práctica de la libertad (Madrid: Siglo XXI, 2002); Pedagogía de los sueños posibles (Buenos Aires: Siglo XXI, 2015), 192; Peter Mclaren, Pedagogía crítica y cultura depredadora (Barcelona: Paidós, 1997), 344.

17. Freire. "Pedagogía de los sueños posibles", 43.

18. Zambrano Leal, "Aprendizajes y pedagogía en Philippe Meirieu”, 10-24.

19. Georges Bataille, La oreja de Van Gogh (Madrid: Casimiro, 2011), 34. 
Estos presupuestos implican que se vayan forjando críticas contundentes hacia el modelo tanto de subjetividades como de identidades abismales, contrarrestando incluso los postulados de las élites académicas, económicas, etc., como ilusorios mejoramientos provenientes de políticas "radicales o progresivas" que parecen responder solamente a la perspectiva neoliberal ${ }^{20}$. Ante eso es viable apoyarse en Wallerstein (2007) cuando menciona que el pensamiento contemporáneo difícilmente parece manifestar su deseo de salir del "parroquialismo" y de las fronteras de la racionalidad occidental apuntalada desde el siglo XIX en el cientificismo.

Freire nos ilustra al respecto de la radicalidad subjetiva como un acercamiento político a cualquier estadio o advenimiento de lo real, hechura de lo subjetivo por medio de la historia, puesto que no se hace posible una experiencia sin historia ni por fuera de la historia.

Al fin de cuentas la Historia es un proceso y no se detiene, no se inmoviliza como piensan algunos. Por eso mismo el conflicto se produce en otro nivel, a veces más camuflado, más amortiguado. Pero la radicalidad de la lectura del mundo sigue sin poder ser aceptada por el conjunto de la clase dominante, ya sea por los liberales que se dicen modernos o por los capitalistas trogloditas, profundamente atrasados. La lectura radical del mundo todavía es un peligro para la preservación del status quo 21.

El ser humano se reinventa en la historia, para Freire como un interminable acercamiento a los mundos de la palabra dialógica que se esboza desde cada contexto en el sentido interminable de la lucha y la utopía. Esto conmemora ciertas densidades que la lectura radical del mundo establece sin establecer: que el sentido de lucha de clases no ha desaparecido, que la caoticidad de los significados abismales está extendiéndose y que la posibilidad utópica se asume-asumirá como el devenir de lo distinto ${ }^{22}$.

Si se analiza la idea de Freire de que el conflicto se presenta en un nivel "más camuflado", es decir, dentro de la psique, incluso como intersubjetividad, se puede

20. Aquí es válido desprender una crítica a una posible actualidad de ambos términos provenientes de los discursos socialistas, en los cuales se van acumulando falacias y fascismos que ocultan la inmanencia afirmativa que deberían desprender. En latín radicālis apunta a: ser junto a la raíz, por tanto, pertenecer a algo mundano, terrestre, a algo que se nutre de la tierra. Asimismo en la palabra "progreso" procede de gressus, dar pasos, como también de gradio, peldaño y manera de caminar, lo que implica caminar despacio, mostrando la relación y vecindad de estos términos con lo terrestre, pero al mismo tiempo con la mesura. Situación que, valiéndonos de una analogía, no corresponde o es totalmente contraria a enunciados contemporáneos como "cambio radical” o “Cita Uribe-FARC: ¿progreso a la vista?", y que presupone un empoderamiento de los términos del socialismo moderno en lo que se puede denominar como el vigor de la publicidad del pensamiento de ultraderecha, disponible en: http://www.semana. com/nacion/articulo/uribe-dispuesto-a-reunirse-con-las-farc/499510 (29 de agosto de 2017).

21. Freire, Pedagogía de los sueños posibles, 94

22. Lo distinto como apreciación de la naturaleza y al mismo tiempo de lo desconocido. Un ejemplo podría ser la condición experiencial del artista representado por Van Gogh, donde la "radiación", así como la "explosión" y la "llama" serán atributos de la otra perspectiva humana que permite la salida de la mismidad y pasividad a la que los dioses, como cánones de antaño, han condenado la obra y la creación de los seres humanos. Véase: Bataille, La oreja de Van Gogh, 45. 
establecer una comparación con la idea de Baudrillard sobre un "espectro del ser" que es dispersada por el consumismo mass mediático y del marketing como una "aparición" constante en la mayoría de las relaciones sociales, aclamando un velo en el que el sujeto se posiciona en el sistema capitalista desde la figura de un espectro, así lo escribe Baudrillard:

ya no hay un sí mismo propiamente dicho, un Sujeto Mismo, ni tampoco, por lo tanto, alteridad del sí mismo, ni alienación en el sentido propio (...) ESPECTRO de signos y de objetos, de matices y de diferencias, que constituye el fundamento del proceso de consumo y redefine totalmente al individuo ${ }^{23}$.

Con lo anterior Baudrillard enseña que la figuración de lo distinto se construye dentro del velo de una ingenua mismidad. Lo que muestra que la posibilidad ontológica de ser y estar en el mundo de la vida choca con el designio cultural del hiperconsumo y la turbación del espectro de la tekné, técnica espectral porque no hay comprensión y al contrario se asimilan procesos de vaciedad, en la época de los vacíos ontológicos todo signo se diluye en apariencia más no en comprensión de esa apariencia. Problemática del capitalismo global que según Han (2017) estratégicamente no está siendo vista como problemática, sino al contrario como dispositivo de positividad y transparencia. Esto advierte 1) que la sociedad contemporánea puede verse como dispersa y dependiente de una cultura de masas, 2) una primera posibilidad de crítica hacia el ensamble de los dispositivos de control social, incluyendo la escuela y las prácticas educativas, y 3) es preciso indagar críticamente en la correspondencia entre la creciente seguridad (democrática, educativa, científica) y "los negocios" de la racionalidad abismal (empresa y sobreexposición de los cuerpos), en sus formas de permanencia, distribución, y por supuesto, en el drástico adentramiento en la perspectiva neoliberal que también atrae, y al mismo tiempo culpabiliza, al contexto educativo.

Bajo esta crítica tanto Freire $(2002,2015)$ como Baudrillard (2012) están introduciendo un repliegue de saber que esclarece la renovación de los discursos, al contrario de lo que se podría denominar con Boaventura de Sousa Santos ${ }^{24} \operatorname{como}$ la re-solidificación del contenido de una racionalidad abismal. De allí que también sea válida una crítica a los discursos abismales que generalmente se usan dentro de la pedagogía: amo-esclavo, culto-inculto, conocimiento-ignorancia, seguridadcriminalidad, competente-incompetente, empezando por esos conceptos que se han vislumbrado como sobreentendidos o sobrevalorados a partir de una voz de mando que implica fragmentos de una libertad inclinada a lo hegemónico ${ }^{25}$,

23. Jean Baudrillard, La sociedad de consumo. Sus mitos, sus estructuras (Madrid: Siglo XXI, 2009), 246247.

24. De Sousa Santos, "Descolonizar el saber. Reinventar el poder".

25. Siguiendo los estudios del profesor Armando Zambrano Leal $(2009,2012)$, puede mostrarse en detalle el sentido de los conceptos que ya se han asimilado como propios del discurso educativo, como "competencia”, "objetivo", "evaluación”, que más bien entran a adoptar posturas políticas tradicionales y conservadoras a partir de la defensa y redistribución de un tipo de discursos que operan desde una racionalidad hegemónica. 
cualquiera que sea, pero el deber es reproducir la inclinación, lo que evidencia in-situ la propagación y/o promulgación de la verticalidad del sentimiento de la deuda y de la culpa (schuld) que el capitalismo global asienta en la psique, en las relaciones humanas, y por tanto, en el presente social y educativo.

\section{La ecología de saberes explicada a los jóvenes ${ }^{26}$}

En este apartado se busca reflexionar sobre una problemática demasiado actual para la pedagogía: ¿influye el sistema-verdad-capitalista contenido en la racionalidad abismal en la vida del ser humano, específicamente, en el pensar de los jóvenes y en su relación con el mundo de la vida? Si se habla de "juventud" desde el contexto latinoamericano se tendrán respuestas abismales para este término, representaciones provenientes de la educación colonial neogranadina que generalmente refiere a la juventud como algo menor o a algo ignominioso e incierto. Un ejemplo es la definición de la pedagogía clásica fundada en la visión del discípulo-alumno, literalmente presentado como el que no tiene luz, es decir, el que permanece en la oscuridad o en la penumbra del ser y del conocer ${ }^{27}$.

Por eso el criterio de juventud puede reafirmarse a partir de interpretaciones que susciten otras comprensiones, dando lugar a fugas que contrarresten el peso hegemónico. Es por eso que el concepto de juventud (como otras categorías, ideas, conceptos divisados como mínimos, peligrosos e infames a conveniencia de la ideología hegemónica) puede adoptar sus representaciones y huellas de manera crítica siguiendo lo que Boaventura de Sousa Santos llama "el pensamiento posabismal" que permitirá comprender el mundo social en relación al devenir de una "ecología de saberes". Para una mejor comprensión dividiremos el sentido de estos conceptos en tres momentos:

A) El pensamiento abismal es lo que caracteriza la racionalidad eurocéntrica: la creación de abismos sobre el pensamiento, sobre la vida humana y natural. Un abismo es una condición de explotación y subordinación, una metáfora para aplicar la seguridad de la globalización, el hiperconsumo y la homogenización y así dividir el mundo en una cartografía hipermoderna que exhibe una "sociedad hegemónica desarrollada" y unas "sociedades coloniales" 28.

No es dialéctica sino dicotomía, o más bien un intento por suprimir la condición dialéctica del mundo y establecer la insoportable continuidad de lo mismo, en

26. Se toma como referencia el título del texto de Santiago Castro-Gómez La postcolonialidad explicada a los niños (Bogotá: Editorial Universidad Javeriana, 2005). En este apartado se trata de hacer una aproximación a las ideas del portugués Boaventura de Sousa Santos expresadas en sus obras Descolonizar el saber. Reinventar el poder. y Democracia y transformación social, que sirven como base teórica de este artículo.

27. En este punto cabe resaltar la perspectiva educativa que la escuela tradicional latinoamericana tuvo para la mujer, mostrándola como mero receptáculo de la cultura e idiosincrasia colonial, ya que la niña específicamente era instruida en labores del hogar, en la escritura de planas y en la adopción de los preceptos morales propios de la mujer cristiana y virtuosa. Véase: Martínez Boom. Verdades y mentiras sobre la escuela, 135-136.

28. De Sousa Santos, "Descolonizar el saber. Reinventar el poder", 31-32. 
relación a lo que Han (2017), denomina como la hipercomunicación actual que suprime los espacios de silencio soledad, que para el contexto latinoamericano cabría en la idea de Santos acerca de la manutención de la racionalidad abismal. A sabiendas que logrando dicha continuidad en (o por medio de) la colonización se re-producirían subhumanos y submundos, teniendo como resultados: desaparición de conocimientos y saberes fuera de la racionalidad abismal, así como los campos de trabajo y subsistemas que se invisibilizan por medio de intervenciones "humanitarias" o simplemente por medio de la brutal intervención policiva.

Según Boaventura esto admite que se refuercen las "líneas globales abismales" por medio de dos distinciones del conocimiento: lo epistemológico y lo jurídico, que marchan en correlación con divisiones políticas, creación de franjas poblacionales, zonas de guerra, de miseria, de explotación, cartografías y epistemologías que operan en o desde la desigualdad corporal y psíquica, pero que al mismo tiempo se usan para la invisibilidad y apropiación de territorios y vidas. Así lo expone el autor:

La humanidad moderna no es concebible sin la subhumanidad moderna. La negación de una parte de la humanidad es un sacrificio, ahí se encuentra la condición de la afirmación de esa otra parte de la humanidad la cual se considera a sí misma como universa. El pensamiento moderno occidental avanza operando sobre líneas abismales que dividen lo humano de lo subalterno de tal modo que los principios humanos no quedan comprometidos por prácticas inhumanas. Las colonias proveyeron un modelo de exclusión radical que prevalece hoy en día en el pensamiento y práctica occidental moderna como lo hicieron durante el ciclo colonial. Hoy como entonces, la creación y negación del otro lado de la línea son constitutivas de los principios y prácticas hegemónicas. Hoy como entonces, la imposibilidad de la copresencia entre los dos lados de la línea se convierte en suprema. Hoy como entonces, la civilidad legal y política en este lado de la línea se presupone sobre la existencia de una completa incivilidad en el otro lado de la línea. Guantánamo es hoy una de las más grotescas manifestaciones de pensamiento legal abismal, la creación del otro lado de la línea como una no área en términos políticos y legales, como una base impensable para el gobierno de la ley, los derechos humanos, y la democracia ${ }^{29}$.

Lo anterior establece que el mundo hipermoderno no es concebible sin la reducción del otro, el mundo ya no aparece como el mundo de la vida sino que es el globo de la civilidad logocéntrica y científica, mucho menos hay lugar para el mundo de la "filosofía" que está del otro lado de la línea. De allí que aún se mantenga la idiosincrasia colonial como forma interna y cultural de sometimiento, de inclinación, manutención de jerarquías y extensión de docilidad, acción que aumenta conjuntamente con las tendencias de inclusión social y ayudas

29. De Sousa Santos, "Descolonizar el saber. Reinventar el poder", 38-39. 
humanitarias. Colonialismo, tal cual como Boaventura de Sousa Santos ${ }^{\mathbf{3 0}}$ lo propone: todavía vigente por medio de la imposición de leyes abismales que se manifiestan mediante prohibición de lenguas, reducción de expresiones artísticas o literarias, por medio de la imposición religiosa y cultural, por la destrucción de saberes y tradiciones.

Del mismo modo se vislumbra una cultura-mundo cuya bandera es el mensaje de la acumulación/desorientación, debido a que la "cultura se vuelve mundo de marcas y consumo, y el mundo comercial se vuelve más o menos cultural"31, operando así sobre el bienestar y el malestar de gran parte de la sociedad. Promoviendo la re-producción de la hegemonía, de la invisibilización de la alteridad, la reproducción de la violencia. Ante esto Boaventura de Sousa Santos muestra un posible presupuesto: la "injusticia social está, por tanto, íntimamente unida a la injusticia cognitiva global"32, lo que enseña una admirable detracción a la cultura capitalista contemporánea, a sus operaciones mercadotécnicas sobre las subjetividades, pero también es una sacudida al espacio de lo educativo en el sentido de que se está apartando dócilmente de la reconstrucción ontológica de lo humano.

Según Boaventura de Sousa Santos la astucia del capitalismo global (es decir, de sus élites académicas y políticas) radica en mantener el ocultamiento de la línea que separa la realidad humana y natural, por medio de la racionalidad cognitiva-instrumental que defiende los postulados y principios del mercado y la consolidación de una tecnicidad ontológica-financiera ${ }^{33}$. Su pensamiento se presenta así como una apuesta crítica y radical ante la "nueva esclavitud" derivada de la asimilación del pensamiento abismal. Y según Santos esta "nueva esclavitud" propuesta y defendida por el capitalismo global no es la duración de lo concreto, por tanto es necesario asumir lo real-concreto desde una posibilidad ética y política.

Lo que muestra una posible relación con la invitación del filósofo Alain Badiou a reafirmar el sentido de la ética en la realidad contemporánea, quien está de lado de una postura crítica que valora la crítica a la racionalidad occidental, al escribir que:

30. De Sousa Santos, "Descolonizar el saber. Reinventar el poder".

31. Lipovetsky y Serroy. "La cultura-mundo", 76.

32. De Sousa Santos, "Descolonizar el saber. Reinventar el poder", 39.

33. Es un ejemplo claro es la posición de las élites del capitalismo en su afán de estandarizar el neoliberalismo, en este caso, aprendizaje técnico para servir y corresponder a la racionalidad abismal y a la jerarquización de la élite moderna. Como referente claro, desde lo irónico del ser colombiano, puede tenerse al exalcalde Cartagena, Manuel V. Duque, quien pidió en su mandato reforzar el aprendizaje técnico en los estudiantes de educación media, antes que un aprendizaje filosófico, al cual depreció y hasta propuso eliminar de las escuelas, información disponible en http://www.elespectador.com/ noticias/nacional/bolivar/de-le-sirve-filosofia-un-joven-pobre-alcalde-de-cartage-articulo-664122 (30 de agosto de 2017). Meses después el honorable gobernante es investigado por corrupción, concierto para delinquir, cohecho y tráfico de influencias, posteriormente fue imputado por los anteriores delitos. Información disponible en: http://www.elcolombiano.com/colombia/la-fiscaliacapturo-a-manuel-vicente-duque-alcalde-de-cartagena-IE7035587 (30 de agosto de 2017). 
La ética es contemporánea, después de décadas de valientes críticas al colonialismo y al imperialismo, de una sórdida autosatisfacción de los "occidentales", de la machacona tesis según la cual la miseria del tercer mundo es el resultado de su impericia, de su propia inanidad, en resumen de su subhumanidad ${ }^{\mathbf{3 4}}$.

B) Ante esa definición de "subhumanidad" De Sousa Santos propone una dimensión crítica de pensamiento que relaciona autonomía, alteridad, emancipación y pensamiento crítico, a lo que el pensador portugués llama el "pensamiento posabismal", que inspecciona el sufrimiento de estas exclusionesexplotaciones, así como las nuevas formas de esclavitud que aquejan lo sociocultural y el entorno natural, lo que puede ser comparado con la idea de Wallerstein (2007) de rechazar la terrible distinción ontológica entre seres humanos y naturaleza que es inaugurada por la racionalidad eurocéntrica. Por eso el pensamiento posabismal puede reconocerse siguiendo a Boaventura de Sousa Santos ${ }^{35}$ como parte de una "ecología de saberes" que se compromete a ser alternativa de las alternativas para enfrentar la época de la crisis del capitalismo y así mismo resistir la globalización neoliberal ${ }^{36}$.

De esta manera el pensamiento posabismal es una ruptura radical con la asimilación de modos de ser y estar derivados de la lógica capitalista, "una ruptura radical con los modos occidentales modernos de ser y actuar"37, pero también una apuesta para que el ser humano contemporáneo pueda vivir por fuera de las líneas globales y del pensamiento hegemónico. Debido a que resistiendo el uso hegemónico de los conceptos y las teorías, estableciendo diálogos entre saberes se puede mostrar la creación de "variedades oposicionales" que sean el presupuesto de una diversidad epistemológica, pero al mismo tiempo, de una resistencia y cultura política, debido a que "el pensamiento posabismal proviene (...) de la idea de que la diversidad del mundo es inagotable y que esa diversidad todavía carece de una adecuada epistemología (...) puesto que la diversidad epistemológica del mundo todavía está por construirse"38.

C) El concepto de crisis en la actualidad no es una oportunidad de transformación sino un brutal exceso de temporalidad. Según de Sousa Santos la crisis se ha mantenido históricamente lo que no da lugar a una transformación sino más bien a un estancamiento en lo abismal. ¿Y de qué crisis estamos hablando? Sobre la sin salida del modelo capitalista de desarrollo que, según Santos, constituye su inmediato presente en la actual crisis del paradigma del progreso intentando (...) escapar por medio de soluciones autoritarias que no harán

34. Alain Badiou. La ética (Madrid: Herder, 2004), 38.

35. De Sousa Santos, "Descolonizar el saber. Reinventar el poder".

36. En este punto De Sousa Santos establece que un horizonte de posibilidad, si se busca comprender el pensamiento posabismal, radica en los movimientos sociales, sobre todo en los pueblos indígenas, donde se puede sentir-pensar la otra parte de la lógica, la otra parte del territorio del conocimiento humano, que precisamente ha estado invisivilizado por haber sido considerado como "subhumano", "irracional", y actualmente como "ilegal".

37. De Sousa Santos, "Descolonizar el saber. Reinventar el poder", 51.

38. De Sousa Santos, “Descolonizar el saber. Reinventar el poder”, 50. 
más que agravar la actual crisis de legitimidad y que, debidamente expuestas por las fuerzas sociales, podrán incluso provocar una crisis de hegemonía, o sea, una crisis en la que, además de que las soluciones políticas y sociales del estado capitalista dejen de ser objeto de un consenso ampliado (lo que lleva a cabo en la crisis de legitimidad), sea posible pensar una alternativa política y social radicalmente diferente y traducida a acciones políticas organizadas ${ }^{39}$.

Crisis que toma su materialidad en la bifurcación política de la época, situación que al seguir las ideas de Boaventura de Sousa Santos, sin duda afecta el entramado de lo estatal, porque dentro de la noción de lo público establecida por ese "consenso ampliado" que mayoritariamente pone en práctica la ideología del sector empresarial y bancario (ODCE para Latinoamérica y OAL, GEA, Corficolombiana, entre otras para el caso colombiano), también se exterioriza el "retorno del colonizador"40 que simultáneamente coincide con la re-aparición de los fascismos y el fortalecimiento de la ultraderecha (retorno del Ku-Kux-Klan en Estados Unidos $^{\mathbf{4 1}}$, el uribismo se consolida como la mayor fuerza política en Colombia ${ }^{\mathbf{4}}$ ), que van dando lugar a los "campos de asesinato" (Siria, Irak, Afganistán como objetivo de civilización por apropiación y violencia ${ }^{43}$ ), a la apropiación de "zonas salvajes" (la selva amazónica como objetivo de industrialización ${ }^{44}$ ), y en general, a la destrucción de la vida (como objetivo de perpetuación del capital).

De esta manera, siguiendo las ideas de Boaventura se puede hablar de crisis en las dimensiones de legitimidad estatal, en el modelo científico, en la política y en la democracia, lo que promueve una crisis de pensamiento, situación que involucra al acto educativo en toda su consistencia práctica y teórica. De hecho, Boaventura de Sousa Santos, establece presupuestos sobre una serie de incertidumbres que coexisten en el mundo contemporáneo a través de una “injusticia cognitiva” $\mathbf{4 5}$, que es vivida en la cotidianidad de los grupos sociales, como limitación al aprendizaje de otros conocimientos, pero sobre todo en la relación excluyente e impositiva que se ha diseñado en las prácticas del ser humano con la trasformación del conocimiento.

39. De Sousa Santos, "Democracia y transformación social”, 144-145.

40. De Sousa Santos, "Descolonizar el saber. Reinventar el poder", 41.

41. Para ampliar la descripción de este punto es recomendable consultar la información que se encuentra disponible en: https://www.elespanol.com/mundo/america/eeuu/20170812/238476468_0.html (30 de agosto de 2017).

42. Esta información se encuentra disponible en: http://www.semana.com/nacion/articulo/la-derechaes-la-nueva-fuerza-politica-del-pais/394412-3 (miércoles, 30 de agosto de 2017).

43. Disponible en: http://www.hispantv.com/noticias/defensa/328640/objetivo-eeuu-invasion-afganis tan-atacar-iran y en: http://www.telam.com.ar/notas/201704/185691-siria-afganistan-trump-bom bardeos-opinion.html (31 de agosto de 2017).

44. El Espectador, disponible en: http://www.elespectador.com/noticias/medio-ambiente/indigenas-seoponen-perforacion-petrolera-en-el-amazonas-ecuatoriano-articulo-704750 (31 de agosto de 2017).

45. Estas incertidumbres Boaventura de Sousa Santos las define como "incertidumbre del conocimiento", "incertidumbre de la democracia", "incertidumbre de la naturaleza", "incertidumbre de la dignidad", identificadas de esa manera por el autor para delimitar las diversas intensidades e impactos de estas incertidumbres en la vida de las personas y las comunidades. De Sousa Santos, "Democracia y transformación social”, 26-33. 


\section{Hacia una pedagogía emparentada a una ecología de saberes}

Este concepto implica la idea de prudencia así como el reconocimiento de lo distinto como parte de la historia del conocimiento humano y natural. La Naturaleza (die Natur) como parte de la esfera ontológica e inmanente de lo humano (Pacha-Mama). Boaventura de Sousa Santos explica que esta forma de saber emerge como "interconocimiento", como estrategia y posibilidad contrahegemónica y como alternativa poscapitalista. Pluralidad e interconocimiento, allí se hace contemporánea la verdadera constitución (beschaffenheit) y se hace posible un enfrentamiento a la intolerancia, a la mismidad, a los campos de concentración de guerra y hasta a los más impúdicos soberanos.

Una ecología de saberes se basa (porque basarse también es un deseo en-latierra), en el reconocimiento de la pluralidad de saberes y valores heterogéneos, en sus interconexiones, en su discontinuidad-continuidad, heterogeneidad y autonomía. Advierte el "cosmopolitismo subalterno" como medio de resistencia que debe ser comprendido como "pensamiento ecológico", así mismo asumir una "copresencia radical" que esté por fuera de la guerra y la depreciación del mundo, estableciendo una interrelación entre "saberes e ignorancias" sin caer en el despotismo de creer que el saber exacto y seguro es el de la ciencia moderna, sino que esta hacer parte de esa urgente "ecología de saberes" que es logos, pero también mythos, y así mismo acción que se fuga de la "vigilancia epistemológica" actual ${ }^{\mathbf{4 6} .}$

\section{Conclusiones}

Como se mostró las líneas globales resuenan desde lo jurídico y lo epistemológico basado en la razón instrumental y en la lógica capitalista que es propagada por el régimen bancario mundial. Un régimen donde la emancipación y la regulación se insertan en las subjetividades para hacer parte del ocultamiento mismo de estas líneas y divisiones globales.

Esta división implica que en el mundo se aplique una re-colonización o el advenimiento de mesianismos o tiranías que traen fascismos como medios de violencia y apropiación-desapropiación. Situación que pone en vilo los modos de ser y estar de lo sociocultural, y por ende, de lo educativo, que parecen estar siendo alimentados en la actualidad por el neoliberalismo, lo que da paso a la emergencia de un pensamiento posabismal, que todavía permanece en estado embrionario, pero que será preciso dentro de su imprecisión para crear "nuevas constelaciones de significados en lo que concierne al entendimiento y a la transformación del mundo" 47 .

46. De Sousa Santos, "Descolonizar el saber. Reinventar el poder”, 48-55.

47. De Sousa Santos, “Descolonizar el saber. Reinventar el poder”, 49. 
Una renovación de los discursos y de la epistemología pedagógica va en contra de la racionalidad solidificada en la arbitrariedad cientificista y en el colonialismo, de allí su imprescindible posibilidad de emergencia como parte de una ecología de saberes. Por eso es factible el sentimiento utópico, más que sensible, impredecible, insatisfecho, no obstante denunciando que la satisfacción nihilista ya está dentro y rocosa como un baldío re-explorado en cada dígito que acumula y vende. Sin embargo, parafraseando a Nietzsche (2008), una situación conmovedora para cualquier época es que se debe superar el nihilismo incluso si la educación del mundo está en juego, porque la educación del hombre siempre ha estado en juego.

Para finalizar podemos decir que los autores anteriormente estudiados siguen la ardua convicción de estar de lado de lo que todavía no llega, es decir, propender el sentimiento ambulante e incierto de la utopía de una pedagogía latinoamericana (carente de todo nacionalismo) como la búsqueda inacabable de alternativas, que no correspondan a la mismidad ideológica ni a los esquemas de dominación tan aceptados por la efímera identidad de los medios de comunicación y los discursos de las asunciones dogmáticas, ya sean políticas, culturales, religiosas y hasta multimediales. La radicalidad es parte del acontecimiento de una ecología de saberes.

Se concibe una flor en la tierra y los colores llegan y se la siembra de nuevo en lo oscuro y en la imaginación de alguien, para que él sea quien la vuelva a sembrar, agüita, tierrita y así hasta que llegue la luna nueva. 


\section{REFERENCIAS BIBLIOGRÁFICAS}

Bataille, Georges, La oreja de Van Gogh. Madrid: Casimiro. 2011.

Baudrillard, Jean, La sociedad de consumo. Sus mitos, sus estructuras. Madrid: Siglo XXI, 2009.

Comenio, Juan, Páginas escogidas. Buenos Aires: A-Z editora, 1996.

Deleuze, Gilles, Dos regímenes de locos. Buenos Aires: Pre-textos, 2008.

De Sousa Santos, Boaventura, Descolonizar el saber, reinventar el poder. Santiago de Chile: LOM, 2014.

De Sousa Santos, Boaventura, Democracia y transformación social. Bogotá: Siglo XXI, 2017.

Freire, Paulo, La educación como práctica de la libertad. Madrid: Siglo XXI, 2002.

Freire, Paulo, Pedagogía de los sueños posibles. Buenos Aires: Siglo XXI, 2015.

Han, Byung-Chul, La expulsión de lo distinto. Madrid: Herder, 2017.

Hoyos Vásquez, Guillermo, Ensayos para una teoría discursiva de la educación. Bogotá: Civitas, 2012.

Lipovetsky, Gilles y Serroy, Jean, La cultura-mundo. Barcelona: Anagrama, 2010.

Martínez Boom, Alberto, Verdades y mentiras sobre la escuela. Bogotá: Editorial Aula, 2015.

Nietzsche, Friedrich, Fragmentos póstumos. Madrid: Tecnos, 2008.

Noguera Ramírez, Carlos, “La constitución de las Culturas pedagógicas modernas: una aproximación conceptual”. En: Revista Pedagogía y Saberes. Universidad Pedagógica Nacional. № 33 (2010): 9-25.

Wallerstein, Immanuel (Coord.), Abrir las ciencias sociales. México: Siglo XXI, 2007.

Zambrano Leal, Armando, "Aprendizajes y pedagogía en Philippe Meirieu”. En: Revista Praxis Educativa. Universidad nacional de La Pampa. $\mathrm{N}^{\circ} 13$ (2009): 10-24.

Zambrano Leal, Armando, “Gobernanza de la escritura: la escisión entre modernidad e hipermodernidad "la cita y el paréntesis", Revista Praxis \& Saber. Vol. 8. N16, Universidad Pedagógica y Tecnológica de Colombia (2017): 205-224. 